\title{
Krukenberg tumor in a young female arising from a primary adenocarcinoma of stomach: a case report
}

\author{
Riddhi Paramar, Mansi Davda, Navin Patel, Keval Arvindbhai Patel*
}

\begin{abstract}
Department of Pathology, Gujarat Adani Institute of Medical Sciences, KSKV Kachchh University, Bhuj, Gujarat, India
\end{abstract}

Received: 13 April 2021

Accepted: 05 May 2021

\section{*Correspondence:}

Keval Arvindbhai Patel,

E-mail: kevalapate192@gmail.com

Copyright: (C) the author(s), publisher and licensee Medip Academy. This is an open-access article distributed under the terms of the Creative Commons Attribution Non-Commercial License, which permits unrestricted non-commercial use, distribution, and reproduction in any medium, provided the original work is properly cited.

\begin{abstract}
Krukenberg tumor is a malignancy of ovary that metastasizes from a primary site. Krukenberg tumors are uncommon and account for less than $2 \%$ of all ovarian tumors. It is usually a bilateral involvement of ovaries from the metastatic deposit from adenocarcinoma of the stomach. Krukenberg tumors mostly occur after 40 years. Metastatic ovarian tumors in young age are very rare. Here, we reported a very rare case of bilateral Krukenberg tumors of the ovaries arising from a primary adenocarcinoma of the stomach in a 20 year old Indian female.
\end{abstract}

Keywords: Krukenberg tumor, Metastasis, Ovarian cancer, Stomach cancer

\section{INTRODUCTION}

Friedrich Ernst Krukenberg, a German gynecologist and pathologist described what he presumed was a new type of primary ovarian neoplasm, who called it sarcoma ovary muco cellulare. ${ }^{1-3}$ They refer to a malignancy in the ovary that metastasizes from a primary site, classically the gastrointestinal tract and breast. ${ }^{4}$ The stomach is the primary site in the majority $(70 \%)$ of Krukenberg tumor cases, followed by carcinoma of the colon, appendix and breast. Krukenberg tumor is considered as a late-stage disease with poor prognosis and may account for 5\% to $30 \%$ of metastatic cancers to the ovaries. ${ }^{5-8}$ It is bilateral in $80 \%$ of the cases. ${ }^{9}$ The frequency of Krukenberg tumor in the population studied contrasts with that of gastric carcinoma. For example, Krukenberg tumor accounts for a significant proportion (17.8\%) of all ovarian cancers in countries such as Japan, which has a high prevalence of gastric carcinoma. ${ }^{10}$

\section{CASE REPORT}

A 20 year old unmarried female presented with generalized abdominal pain and abdominal distention for
10 days duration. Physical examination revealed a distended abdomen filled with fluid. Ultrasound abdomen (USG) and magnetic resonance imaging (MRI) showed large heterogenous enhancing solid-cystic lesion of size $11.7 \times 7.5 \mathrm{~cm}$ in midline pelvis suggest possibility of right ovarian tumor fibro-thecoma. Gross ascites around 2800 ccs free fluid wasnoted. Mild to moderate right pleural effusion with no evidence of focal liver lesion or lymphadenopathy. Possibility of Meigs syndrome (ovarian fibroma+pleural effusion+ascites). Complete blood count showed leucocytosis $(14,900$ /cumm) with neutrophilia (90\%). CA-125 was $217 \mathrm{U} / \mathrm{ml}$. Based on clinical, laboratory and image analysis, the ovarian tumors were diagnosed as primary ovarian carcinoma. Ascitic fluid cytology showed no malignant cells. A tentative diagnosis of Meigs syndrome was made. On exploration, right ovary replaced by solid mass and left sided ovary showed small solid growth along with mild ascites. She underwent right oophorectomy along with a tissue growth from left ovary was received for histopathological evaluation.

The specimen of right ovarian tumor measured $12 \times 8.5 \times 3$ $\mathrm{cm}$ in size and weighed $410 \mathrm{gms}$. The tumor was well 
circumscribed, solid and external surface showed a bosselated contour. The cut surface of it had solid appearance and had grayish white and yellowish appearance (Figure $1 \mathrm{~A}$ and $\mathrm{B}$ ).

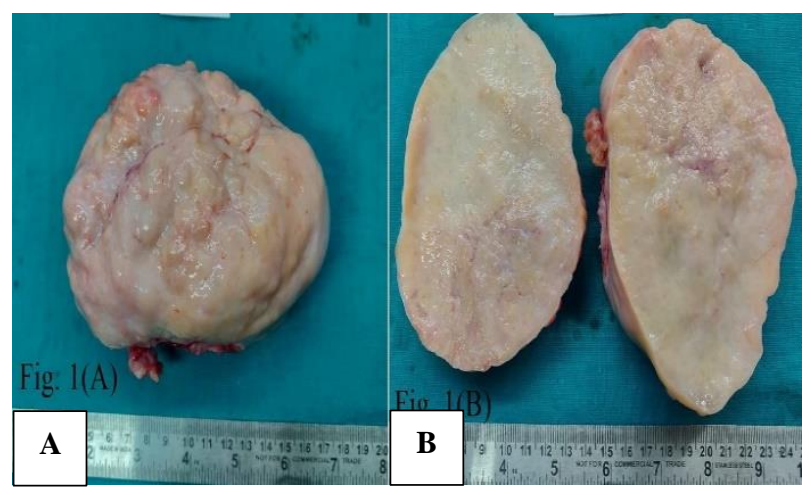

Figure 1: (A) the right ovarian tumor is enlarged with a well-circumscribed, solid and bosselated contour; (B) cut section shows solid, grayish white to yellowish appearance.

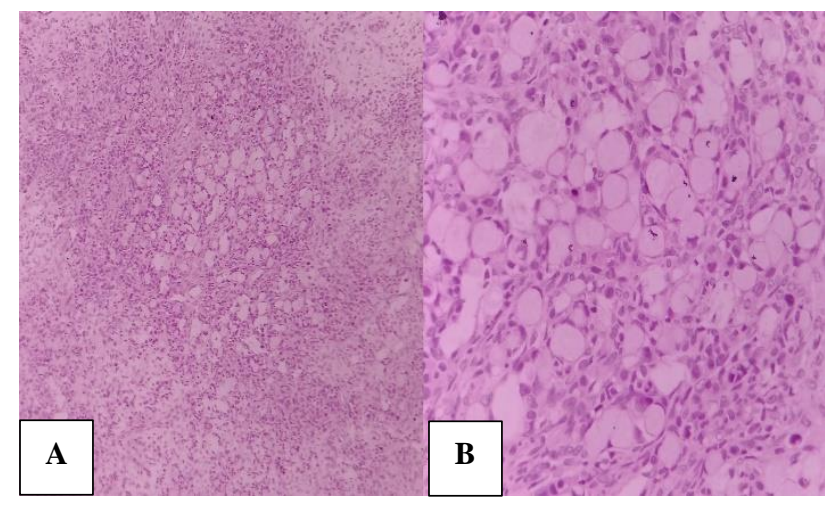

Figure 2: (A) histology shows numerous signet ring cells present within a cellular stroma (right ovarian tumor) (H and E x100); (B) signet ring cells with eccentric hyperchromatic nuclei and eosinophilic granular cytoplasm with mucin vacuoles (right ovarian tumor) (H and $\mathrm{E} \times \mathbf{4 0 0})$.

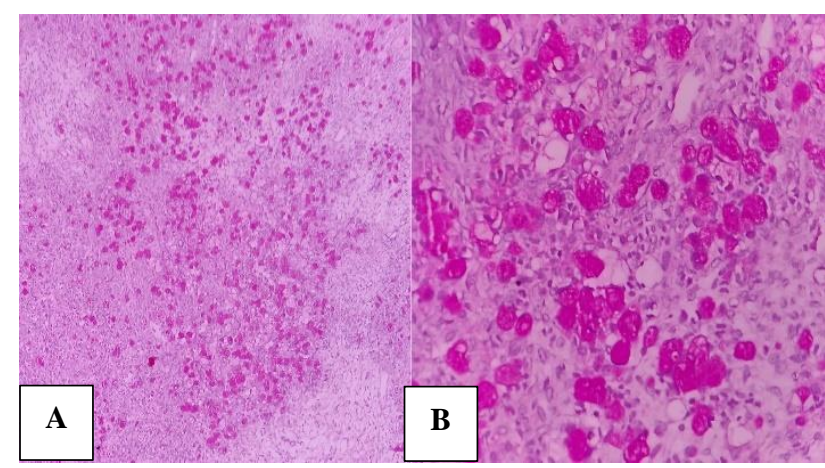

Figure 3: (A) shows intense and diffuse cytoplasmic PAS positivity to signet ring cells (right ovarian tumor) (PAS stain x100); (B) shows intense and diffuse cytoplasmic PAS positivity to signet ring cells.

(Right ovarian tumor) (PAS stain $\mathrm{x400).}$

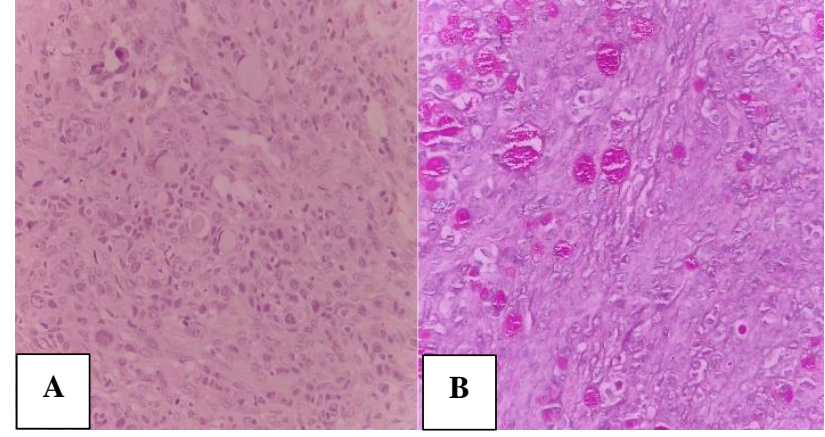

Figure 4: (A) Krukenberg tumor shows some signet ring cells with a bull's eye or targetoid appearance

containing a large vacuole with a central or paracentral droplet of mucin that appears as an eosinophilic body (left ovarian growth) $(\mathrm{H}$ and $\mathrm{E}$ X400); (B) shows signet ring cells stained with periodic acid Schiff stain (left ovarian growth) (PAS stain

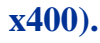

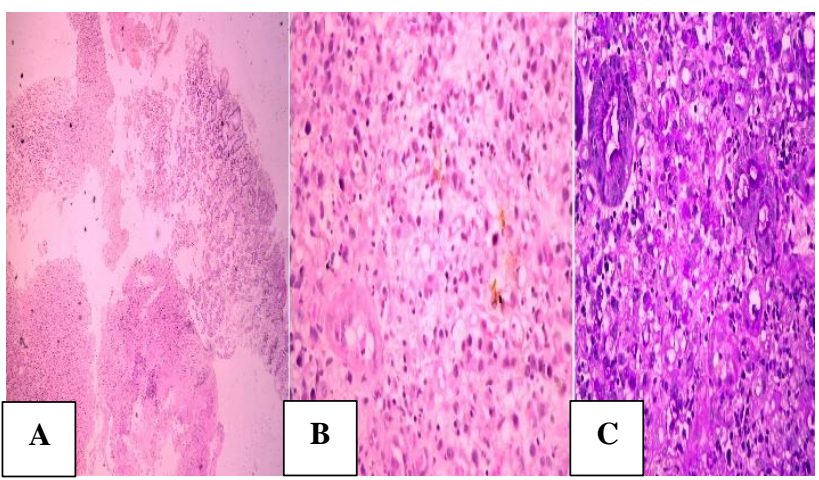

Figure 5: (A) histology shows mucosa composed of normal glands and tumor cells (gastric biopsy) (H and E x100); (B) tumor cells are arranged in cords and dispersed singly having hyperchromatic nuclei and peripherally pushed nuclei (gastric biopsy) ( $\mathrm{H}$ and $\mathrm{E}$ x400); (C) histology shows PAS positive tumor cells (gastric biopsy) (PAS stain x400).

Separately sent two pieces from left ovarian growth, each of which measured $2 \times 1.5 \times 1.2 \mathrm{~cm}$ and $3 \times 0.8 \times 0.5 \mathrm{~cm}$. It was also solid in consistency and grayish white to yellow in color. Microscopic examination revealed a right ovarian tumor composed of epithelial and stromal components. The epithelial component is mainly composed of mucin laden signet ring cells with eccentric hyperchromatic nuclei. The cytoplasm of the signet ring cells is eosinophilic and granular (Figure $2 \mathrm{~A}$ and B), pale and vacuolated and having a bull's eye (targetoid) appearance containing a large vacuole with a central to paracentral eosinophilic body composed of a droplet of mucin. Some tumor cells may lack a mucin vacuole. Mitotic activity was sparse. The mesenchymal component is composed of plump and spindle-shaped cells with minimal cytological atypia or mitotic activity. Periodic acid schiff (PAS) stain showed intense and diffuse cytoplasmic PAS positivity to signet ring cells (Figure $3 \mathrm{~A}$ and $\mathrm{B}$ ). Left side infiltrated ovarian tissue 
showed normal ovarian parenchyma located peripherally and infiltration by tumor cells, most having morphology of signet ring cell appearance (Figure $4 \mathrm{~A}$ and B).

To determine the primary malignant site, the patient underwent USG of breast which showed normal breast parenchyma and an upper GI endoscopy was performed with the suspicious of primary GI malignancy, which revealed $2 \times 1.5 \mathrm{~cm}$ ulcerated lesion along the antrum and fundus of the stomach. Histopathology showed gastric mucosa, tumor and area of necrosis. The mucosa showed normal glands and beneath it tumor component. The tumor cells are dispersed singly or in cords and they have hyperchromatic nuclei. Most of these tumor cells were distended due to mucin and nuclei were pushed at periphery (Figure $5 \mathrm{~A}$ and $\mathrm{B}$ ). The tumor cells showed abnormal mitotic activity. PAS stain showed intense and diffuse cytoplasmic positivity to signet ring cells (Figure $5 \mathrm{C})$. The diagnosis was made as adenocarcinoma of the stomach. The final diagnosis was gastric adenocarcinoma with bilateral ovarian metastases diagnosed as Krukenberg tumor.

\section{DISCUSSION}

Krukenberg tumor tend to occur in the young female, with an average age of 45 years. ${ }^{11}$ Krukenberg tumor were more common in premenopausal women $(75 \%)$ rather than in postmenopausal women. ${ }^{12}$ Gupta et al and Khurana et al reported Krukenberg tumor in 20 years and 13 years of women, respectively. ${ }^{13,14}$ Common presenting symptoms are usually related to ovarian involvement, the most common of which are abdominal pain and distension (mainly because of the usually bilateral and often large ovarian masses). The remaining patients have nonspecific gastrointestinal symptoms or are

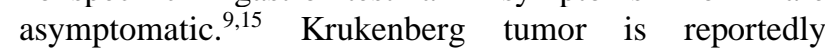
associated with virilization resulting from hormone production by ovarian stroma. ${ }^{16}$ Ascites is present in 50\% of the cases and usually reveals malignant cells. Cetin et al have recently reported a case of Krukenberg tumor with right hydrothorax and ascites that revealed no malignant cells. ${ }^{17}$ This was referred to as Pseudo-Meigs' syndrome. The route of metastasis of gastric carcinoma to the ovaries has been a mystery for a long time, but it is now evident that retrograde lymphatic spread is the most likely route of metastasis as there are several evidence supporting this concept. First, lymphatic permeation at the hilum and cortex is microscopically noted in many cases of Krukenberg tumor. ${ }^{11}$ Diagnosis of the primary carcinoma can be done either preoperatively, during surgery for ovarian metastases or within a few months postoperatively. ${ }^{18}$ The primary tumor is often too small to be detected. In such a situation, the diagnosis of the Krukenberg tumor requires careful radiographic and endoscopic examination of the digestive system to detect primary carcinoma. Radiologically, Krukenberg tumor on abdominopelvic ultrasonography and MRI usually appear as bilateral ovarian masses. The masses are usually solid but can also be cystic. ${ }^{19}$ Krukenberg tumor are bilateral in more than $80 \%$ of the reported cases. The ovaries are usually asymmetrically enlarged, with a bosselated contour. The capsular surface of the ovaries with Krukenberg tumor is typically smooth and free of adhesions or peritoneal deposits. The cut surfaces are yellow or white, they are usually solid, although they are occasionally cystic. ${ }^{11}$ The diagnosis of Krukenberg tumor largely depends on the recognition of their characteristic light microscopic features show diffusely infiltrated by malignant signet-ring cells arranged singly, in cords, or in nests in densely fibroblastic stroma. ${ }^{20}$ Immunohistochemistry (IHC) evaluation can help to differentiate primary ovarian carcinomas from metastatic carcinomas.

Differential diagnosis of classical Krukenberg tumor mainly in two categories, ovarian tumors with signet ring cells containing mucin and ovarian tumors with signet ring cells containing nonmucinous material. Primary mucinous tumors of the ovary can contain cells with signet ring appearance. However, these tumors tend to be more commonly unilateral with a complex papillary pattern. Mucinous carcinoid tumors (either primary or metastatic, most commonly from appendix) enter the differential diagnosis in this group by having cells that may assume signet ring appearance and resemble Krukenberg tumor cells. Although mucinous carcinoid cells stain with mucin stains similar to Krukenberg tumor cells, immunostains for chromogranin and synaptophysin are usually positive and can easily confirm the diagnosis in favor of mucinous carcinoid. Krukenberg tumors must also be distinguished from ovarian tumors that can contain signet ring cells filled with nonmucinous material, including signet ring stromal tumor, sclerosing stromal cell tumor and clear cell adenocarcinoma of the ovary. ${ }^{4,10,18,21-26}$ Immunohistochemistry, which plays an important role in the differentiation of ovarian tumors with signet ring cells containing mucin, Cytokeratin 7 and 20 (CK7 and CK20) is the most commonly used. Primary ovarian carcinomas are almost always immunoreactive to CK7 (90-100\%). Metastatic gastric carcinoma tends to be less frequently positive for $\mathrm{CK} 7$ (55\%) but is positive for CK20 in approximately $70 \%$ of cases. Colorectal adenocarcinomas are usually negative for CK7 but positive for CK20 in most cases. Tumors metastasizing from the appendix are commonly positive for CK20 but positive also for CK7 in 50\% of cases. Therefore, a CK7- or CK20- immunophenotype favours a primary ovarian carcinoma, whereas a CK7- or CK20+ or CK7+ or CK20+ immunophenotype (CK20 positivity, in particular) favours a metastatic gastrointestinal carcinoma. ${ }^{27-29}$ Krukenberg tumor patient prognosis is extremely poor, with average survival times ranging from 3 to 10 months, only $10 \%$ of these patients survive $>2$ years after diagnosis. ${ }^{30}$

\section{CONCLUSION}

Krukenberg tumor is very rare in younger age groups. Diagnosis of Krukenberg tumor with unknown primary 
sites requires careful investigation of the digestive tract and other potential sites. Better awareness of disease in younger patients is important for early diagnosis, fertilitysparing treatment and survival.

Funding: No funding sources Conflict of interest: None declared

Ethical approval: Not required

\section{REFERENCES}

1. Liu AAC, Chen CH, Liu WM, Chang CW. A rare Krukenberg tumor arising from a primary adenocarcinoma of the small intestine. Taiwanese $\mathbf{J}$ Obstet Gynecol. 2018;57(2):319-22.

2. Ruotolo S, Errico ME, Castelli L, Caccioppoli U, Bernardi BD, Guarrasi R, et al. Krukenberg tumor in an 11-year-old girl. J Ped Surg Case Rep. 2014;2(3):150-2.

3. Friedrich K. Uber das Fibrosarcoma ovarii mucocellulare (Carcinomatoides). Arch F Gynak. 1896;50(6):287-321.

4. Rosai J. Ovary. Rosai and Ackerma's Surgical Pathology. 10 ed. St Louis Mosby: Elsevier; 2011:1367-431.

5. Kiyokawa T, Young RH, Scully RE. Krukenberg tumors of the ovary: a clinicopathologic analysis of 120cases with emphasis on their variable pathologic manifestation. Am J Surg Pathol. 2006;30(2):277-99.

6. Young RH. Scully metastatic tumors of the ovary. In: Kurman RJ, ed. Blaustein's Pathology of the Female Genital Tract. 5th ed. Switzerland: Springer Nature; 2002: 1063-101.

7. Prat J. Ovarian carcinomas, including secondary tumor: 10 diagnostically challenging areas. Mod Pathol. 2005;18:99-111.

8. Mambrini P, Giovanini M, Seitz JF, Perrier $\mathrm{H}$, Allemand I, Rabia I, et al. Uterine metastasis revealing gastric adenocarcinoma. Gastroenterol Clin Biol. 1995;19(8-9):725-8.

9. Young RH. From Krukenberg to today: the ever present problems posed by metastatic tumors in the ovary: part I: historical perspective, general principles, mucinous tumors including the Krukenberg tumor. Adv Anat Pathol. 2006;13(5):205-27.

10. Yakusshiji M, Tazaki T, Nishimura H, Kato $\mathrm{T}$. Krukenberg tumors of the ovary: a clinicopathological analysis of 112 cases. Acta Obstet Gynaecol J. 1987;39(3):479-85.

11. Al-Agha OM, Nicastri AD. An in-depth look at Krukenberg tumor: an overview. Arch Pathol Lab Med. 2006;130(111):1725-30.

12. Wu F, Zhao X, Mi B, Feng LU, Yuan NA, Lei F, et al. Clinical characteristics and prognostic analysis of Krukenberg tumor. Mol Clin Oncol. 2015;3(6):13238.

13. Gupta P, Snebold MA, O'Donnelly S. Krukenberg's tumor in the young population. J Am Osteopath Assoc. 1989;89(4):500-2.
14. Khurana P, Sachdev R, Uppal S, Bisaria D. Krukenberg tumor in a 13-year old girl: a rare occurrence. Indian J Pathol Microbiol. 2010;53(4):874-5.

15. Peng W, Hua RX, Jiang R, Ren C, Jia YN, Li J, et al. Surgical treatment for patients with Krukenberg tumor of stomach origin: clinical outcome and prognostic factors analysis. PLoS One. 2013;8(7):8227.

16. De-Palma P, Wronski M, Bifernino V, Bovani I. Krukenberg tumor in pregnancy with virilization: a case report. Eur J Gynaecol Oncol. 1995;16(1):5964.

17. Cetin B, Aslan S, Akinci M, Atalay C, Cetin A. A long surviving case of Pseudomeigs' syndrome caused by Krukenberg tumor of the stomach. Jpn J Clin Oncol. 2005;35(4):221-3.

18. Hale RW. Krukenberg tumor of the ovaries: a review of 81 records. Obstet Gynecol. 1968;32(2):221-5.

19. Kim SH, Kim WH, Park KJ, Lee JK, Kim JS. CT and MR findings of Krukenberg tumors: comparison with primary ovarian tumors. J Comput Assist Tomogr. 1996;20(3):393-8.

20. Kuno I, Hashiguchi Y, Kasai M, Fukuda T, Ichimura $\mathrm{T}$, Yasui T, et al. Krukenberg tumor in a 18-year-oldfemale: a rare case. Eur J Gynaecol Oncol. 2016;37(1):139-41.

21. Lee KR, Young RH. The distinction between primary and metastatic mucinous carcinomas of the ovary: gross and histologic findings in 50 cases. Am J Surg Pathol. 2003;27(3):281-92.

22. Vang R, Bague S, Tavassoli FA, Prat J. Signet ring stromal tumor of the ovary: clinicopathologic analysis and comparison with Krukenberg tumor. Int J Gynecol Pathol. 2004;23(1):45-51.

23. Holtz F, Hart WR. Krukenberg tumors of the ovary: a clinicopathological analysis of 27 cases. Cancer. 1982;50(11):2438-47.

24. Duarte I, Llanos O. Patterns of metastases in intestinal and diffuse types of carcinoma of the stomach. Hum Pathol. 1981;12(3):237-42.

25. Willis RA. The Spread of Tumors in the Human Body. 3rd ed. London, England: Butterworths; 1973: 222-6.

26. Kakushima N, Kamoshida T, Hirai S, Hotta S, Hirayama T, Yamada J, et al. Early gastric cancer with Krukenberg tumor and review of cases of intramucosal gastric cancers with Krukenberg tumor. J Gastroenterol. 2003;38(12):1176-80.

27. Park SY, Kim HS, Hong EK, Kim WH. Expression of cytokeratins 7 and 20 in primary carcinomas of the stomach and colorectum and their value in the differential diagnosis of metastatic carcinomas to the ovary. Hum Pathol. 2002;33(11):1078-85.

28. Wauters CC, Smedts F, Gerrits LG, Bosman FT, Ramaekers FC. Keratins 7 and 20 as diagnostic markers of carcinomas metastatic to the ovary. Hum Pathol. 1995;26(8):852-5.

29. Ronnett BM, Kurman RJ, Shmookler BM, Sugarbaker PH, Young RH. The morphologic 
spectrum of ovarian metastases of appendiceal adenocarcinomas: a clinicopathologic and immunohistochemical analysis of tumors often misinterpreted as primary ovarian tumors or metastatic tumors from other gastrointestinal sites. Am J Surg Pathol. 1997;21(10):1144-55.
30. Jeong HY, Sung TO, Byung SK. Clinical prognostic factors for ovarian metastasis in women with gastric cancer. Hepatogastroenterology. 2007;54(75):955-9.

Cite this article as: Paramar R, Davda M, Patel N, Patel KA. Krukenberg tumor in a young female arising from a primary adenocarcinoma of stomach: a case report. Int J Reprod Contracept Obstet Gynecol 2021;10:2523-7. 